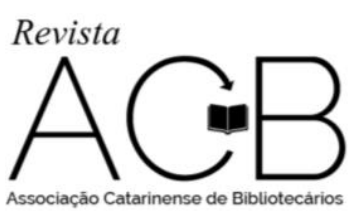

Revista ACB: Biblioteconomia em Santa Catarina, Florianópolis, v. 23, n. 1, p. 92-106, dez./mar., 2018.

\title{
A INCLUSÃO DOS USUÁRIOS COM TRANSTORNO DE ESPECTRO AUTISTA PELA PRÁTICA DO LETRAMENTO INFORMACIONAL NA BIBLIOTECA ESCOLAR
}

\author{
Marcos Pastana Santos ${ }^{1}$ \\ Cládice Nóbile Diniz ${ }^{2}$
}

\begin{abstract}
Resumo: Propõe-se a discussão do letramento informacional para alunos autistas que frequentam a biblioteca escolar desde a educação infantil até o ensino fundamental da escola pública, considerando a adequação dos serviços oferecidos por meio dos conceitos do desenho universal. Investiga os métodos de leitura adotados pelos profissionais da educação para o desenvolvimento da aprendizagem do aluno com deficiência. Analisa o processo histórico da pessoa com autismo e as singularidades da deficiência de modo a construir com equipe multidisciplinar, atividades pedagógicas e biblioteconômicas que viabilizem o acesso a informação e o conhecimento. A metodologia foi quanto aos fins, descritiva e quanto aos meios, bibliográfica, com tratamento de dados qualitativo. Como resultado, destaca que a importância da prática do letramento informacional na biblioteca escolar para o aluno com transtorno do espectro autista e que é necessário repensar os serviços, com os conceitos do desenho universal como um guia de possibilidades.
\end{abstract}

Palavras-chave: Transtorno de Espectro Autista. Biblioteca escolar. Letramento informacional. Desenho universal.

\section{THE INCLUSION OF USERS WITH AUTISTIC SPECTRUM DISORDERS FOR THE PRACTICE OF INFORMATION LITERACY IN THE SCHOOL LIBRARY}

\begin{abstract}
It is proposed to discuss information literacy for autistic students attending the school library from kindergarten to elementary school, considering the adequacy of the services offered through the concepts of universal design. It investigates the reading methods adopted by educational professionals for the development of student learning with disabilities. It analyzes the historical process of the person with autism and the singularities of the disability in order to build with a multidisciplinary team, pedagogical and library activities that enable access to information and knowledge. The methodology was for the purposes, descriptive and as for the means, bibliographical, with qualitative data treatment. As a result, he emphasizes that the importance of the practice of information literacy in the school library for the student with autism spectrum disorder and that it is necessary to rethink the services, with the concepts of universal design as a guide to possibilities.
\end{abstract}

Keywords: Autism Spectrum Disorder. School library. Information Literacy. Universal design.

\section{INTRODUÇÃO}

Em recente encontro de estudantes e egressos de licenciatura em teatro sobre saúde mental, realizado na Universidade Federal do Estado do Rio de Janeiro, uma participante que lecionava na rede municipal carioca de ensino, ao relatar sua experiência com a introdução do ensino inclusivo determinado pela legislação, que entre outros aspecto exige que os alunos com deficiência cursem as aulas junto com os demais, declarou ter percebido nas discussões entre professores sobre como atuar nesse esse novo

\footnotetext{
${ }^{1}$ Doutorando em Humanidades, Culturas e Artes na Universidade do Grande Rio (UNIGRANRIO). Mestre Profissional em Biblioteconomia na Universidade Federal do Estado do Rio de Janeiro. Bibliotecário-Documentalista do Instituto Federal do Rio de Janeiro - IFRJ. E-mail: marcos.pastana@ifrj.edu.br

${ }^{2}$ Doutora em Ciência da Informação na Universidade Federal do Rio de Janeiro (UFRJ). É docente e pesquisadora no Programa de Pós-Graduação em Biblioteconomia e no Departamento de Engenharia de Produção da Universidade Federal do Estado do Rio de Janeiro (UNIRIO). É líder do grupo de pesquisa: Perspectivas da biblioteca como organização criativa na otimização dos recursos de aprendizagem: da acessibilidade à fluência informacional. E-mail: cladice.diniz@unirio.br
} 
contexto, "um grande medo de como lidar com o aluno autista". Essa fala foi endossada por diversos presentes.

Observa-se que essa colocação foi destacada porque, ainda que provenha de olhares críticos, serve para destacar o quanto, de fato, as recentes conquistas legais das pessoas com deficiências estão se apresentando ao sistema educacional brasileiro como um desafio.

Esse clima de preocupação entre os professores reflete na biblioteca escolar, que é parte integrante da escola e sensível ao clima organizacional da instituição onde está inserida. Isso pode ser verificado pelo grande número de bibliotecários que se interessaram em entender e estudar a questão da acessibilidade a partir do momento de sua proposição como objeto de Lei, aumentando o número de estudos publicados sobre o tema nos últimos 20 anos.

Ainda que no caso da deficiência o profissional da biblioteca tenha um panorama mais favorável para a sua atuação, uma vez que o professor em sala de aula interage com todos os seus alunos, concomitantemente, quase todo o tempo ao passo que na biblioteca o atendimento pode ocorrer de forma individualizada ao aluno seu usuário, ele depara-se com a necessidade de dominar conhecimentos sobre as deficiências e sobre a legislação, de adquirir habilidades com softwares e equipamentos assistivos e de dotar-se de atitudes inclusivas e, sobretudo, ter seus serviços muito bem articulado com as exigências impostas pelas práticas na sala de aula e na sala de recursos. De igual forma, desenvolver novas competências.

O autismo, isto é, o Transtorno de Espectro Autista (TEA) foi, a partir de 2012, pelos artigos 1 e 2 da Lei $\mathrm{n}^{\circ}$ 12.764/12 (BRASIL, 2012), reconhecido como uma deficiência, passando as pessoas com esse transtorno a serem alvo de direitos protetivos. O significado do termo autismo é o de estar-se ausente ou perdido. Caracteriza-se pelo distanciamento da realidade que cerca a pessoa com o transtorno. Esta está sujeita a presentar um padrão de comportamento peculiar ou não, havendo casos em que se mostram bastante diferenciados dos demais estudantes. Esse agir atípico no ambiente escolar pode causar dificuldades no bom fluir de seu processo de interação social e trazer-lhe consequências na aprendizagem, assimilação e acomodação dos conteúdos.

A biblioteca escolar precisa atender a esses usuários, incluindo-os, contemplando seus direitos de terem serviços eficazes para adequadamente desenvolverem seus processos de aprendizagem. Para isso, ela é desafiada a ir além de sua problemática, por mais complexa que possa ser e focar na questão de como atender ao usuário com deficiência. E como o lidar com o autista apresentou-se com um ponto significativo, buscou-se aprofundar o conhecimento dessa problemática. 
Os alunos da educação infantil e do ensino fundamental que apresentam esses transtornos poderão se beneficiar, se houver serviços que ofereçam condições favoráveis de acesso à informação na biblioteca escolar da instituição educacional em que estudam. Por esse motivo, o debate sobre a inclusão das pessoas como autismo nos espaços formais de aprendizagem como a biblioteca escolar e o seu processo de ensino-aprendizagem são pertinentes na medida em que o comportamento inapropriado do usuário com o transtorno, a sua dificuldade de interação, comunicação e o repertório restrito de interesse são um desafio para os profissionais de ensino e da biblioteca.

Por outro lado, com o desenvolvimento das tecnologias de informação, a biblioteca escolar vem se dinamizando e ofertando recursos acessíveis para todos os usuários, o que pode ser otimizado com mão de obra especializada, seja pela formação continuada dos profissionais que já atuam na biblioteca, seja por novas contratações. Para se investigar sobre em que estado está a biblioteca escolar quanto aos recursos acessíveis para os usuários autistas, se propôs esta pesquisa, elegendo-se como objetivo central entender sobre até que ponto a articulação entre a sala de aula, a sala de recursos e a biblioteca das escolas municipais da rede pública do ponto de vista dessa comunidade discente.

Contribuir para a compreensão da realidade das bibliotecas escolares brasileiras, diagnosticar o real cenário de oferta de serviços acessíveis e de capacitação dos profissionais que atuam neste espaço são propósitos relevantes para destacar o investimento do poder público em ofertar acessibilidade não somente arquitetônica, mas que perpasse às outras demandas sociais, como a acessibilidade atitudinal, a comunicacional e a programática.

\section{METODOLOGIA}

O sujeito da pesquisa é o aluno autista que frequenta ou não a biblioteca escolar, quanto aos serviços oferecidos ao usuário com Transtorno de Espectro Autista (TEA). O universo da pesquisa são as bibliotecas escolares brasileiras e como os serviços acessíveis deste setor podem possibilitar o acesso à informação e ao conhecimento.

A metodologia foi quanto aos fins descritiva e quanto aos meios, bibliográfica. Os dados foram tratados por método qualitativo.

\section{HISTORICIDADE DO TRANSTORNO DE ESPECTRO AUTISTA}

Fazendo uma intervenção pontual sobre o percurso histórico da compreensão do autismo, se têm na Antiguidade relatos de crianças com comportamentos estranhos, segundo Moreira (2005), que as especificidades relatadas lhe sugerem questionar sobre se não se trataram de casos de crianças autistas. 
Ritvo e Ornitz (1976) descrevem o problema de desenvolvimento de algumas crianças autistas e conceituou que estas apresentavam déficits cognitivos, cuja detecção foi feita por meio de observação clínica de algumas características comportamentais, características essas representadas por distúrbio de percepção, comprometimento na interação social, ansiedade estranha e exagerada.

Os aspectos, conforme a gradação com que se manifesta as características mencionadas no parágrafo acima, geram dois grupos de sintomas:

a) O do Déficit na comunicação e interação social; e

b) O do Padrão de comportamentos, interesses e atividades restritos e repetitivos.

No primeiro grupo, incluem-se os casos de deficiência persistente e clinicamente significativa da comunicação e da interação sociais, manifestada na comunicação verbal e na não verbal usada na interação social; ausência de reciprocidade social; e falência em desenvolver e manter relações apropriadas ao seu nível de desenvolvimento.

No segundo caso, o de Padrão de comportamentos, interesses e atividades restritos e repetitivos, situam-se os manifestados por comportamentos motores ou verbais estereotipados ou por comportamentos sensoriais incomuns; excessiva aderência a rotinas e padrões de comportamento ritualizados; e interesses restritos e fixos (ARAÚJO; LOTUFO NETO, 2014).

Os estudos de Assumpção Junior (1995) conceituam que o Autismo Infantil (AI) deve ser compreendido de forma ampla, com a ocorrência do transtorno englobando uma série de patologias dentro de um mesmo quadro de sinais e sintomas, que incluem a do autista ter dificuldades em ajustar seu comportamento ao contexto social ao qual faz parte, não conseguir responder e/ou entender as emoções de outros sujeitos e terem as interações com seus pares restritas. Ainda para Assumpção Jr. (1995), a síndrome pode ser caracterizada por:

- Movimentos caracterizados por maneirismo e movimentos estereotipados;

- Comprometimento nas esferas motoras, na linguagem e na sua interação social;

- Dificuldade em manter contato visual;

- Dificuldade em compreender o que ouve; e

- Repetição de palavras e frases que ouve.

A falta de habilidade social e emocional dos estudantes com espectro autista costuma dificultar a aproximação das pessoas e dificulta-lhes a criação de vínculos com o ambiente e com as pessoas que o cercam. $\mathrm{O}$ isolamento que aparenta ser característica dos estudantes com espectro autista é resultado não somente de não saberem aproximar-se de forma espontânea de seus colegas, mas também destes seus colegas de não saberem comportar-se de forma inclusiva. 
Para superar a barreira que assim pode ir sendo construída e acabar por isolar o usuário com transtorno de espectro autista, o profissional da biblioteca deve buscar compreender as suas singularidades da situação e em conjunto com outros profissionais do sistema escolar, em atuação multidisciplinar, desenvolver ações para promoção da inclusão por meio do acesso à informação, que é denominado acessibilidade informacional.

Cabe no próximo tópico, ressaltarmos, a legislação brasileira sobre os direitos da pessoa autista e a representação social da biblioteca escolar.

\section{A LEGISLAÇÃO, O AUTISTA E A BIBLIOTECA ESCOLAR}

No que diz respeito à legislação para pessoas com deficiência, tem-se alcançados significativos avanços no direito, quanto à Educação e à Diversidade, pluralidade de atendimento às necessidades educacionais específicas de todas as pessoas que ingressam no sistema público de ensino.

Respaldados por leis, os responsáveis têm o direito garantido de matricular seus filhos no sistema público de ensino sem qualquer restrição, seja de deficiência ou seja de condição sócio-cultural, dentre outras. A Lei que ampara o aluno com espectro autista é a Lei n 12.764, de 27 de dezembro de 2012. Ela representa um marco para esse público que devido a suas peculiaridades de comportamento vinha enfrentado dificuldades para o ingresso e permanência no sistema público de ensino, assim como nas instituições privadas.

Essa Lei é conhecida como Lei Berenice Piana e instituiu a Política Nacional de Proteção dos Direitos da Pessoa como transtorno do espectro autista e estabeleceu diretrizes para sua consecução, dispondo entre elas em seu Art. 2, inciso VII a orientação de de incentivo à formação e à capacitação de "profissionais especializados no atendimento à pessoa com transtorno do espectro autista, bem como a pais e responsáveis". Essa diretriz vem se apresentado como um desafio para as escolas, professores e, em específico, aos profissionais que atuam nas bibliotecas escolares, posto que os estudantes com o transtorno autista demandam uma série de adaptações por apresentarem como característica específica da deficiência o contato social prejudicado, adaptações que incluem adequações do ambiente físico da biblioteca, do comunicacional e das relações interpessoais.

Os estudantes com espectro autista, por apresentarem dificuldades na percepção de expressões faciais diferentes; sensibilidade a ruídos altos; e evitar ou rechaçar o contato visual e físico, requerem pensar-se em uma proposta de trabalho específica do espaço da biblioteca escolar, em tarefa multidisciplinar entre todos os profissionais que atuam diretamente com eles. 


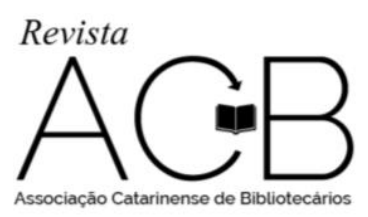

Revista ACB: Biblioteconomia em Santa Catarina, Florianópolis, v. 23, n. 1, p. 92-106, dez./mar., 2018.

Essa situação destaca como importante - trabalho da biblioteca o priorizar a relação com o outro, a afetividade, a comunicação verbal e não verbal para estimular e potencializar a interação do estudante com espectro autista com a leitura, a literatura, com os seus pares e com os demais funcionários da unidade de ensino.

Trabalhos que envolvam a dramatização, variação de linguagem são significativos para os estudantes com autismo, posto que é necessário estimular novos desafios a estes estudantes, a fim de propiciar-lhes o desenvolvimento cognitivo e psicológico, uma vez que a aprendizagem não se restringe aos conteúdos escolares socialmente valorizados.

É preciso olhar cada estudante dentro do espaço escolar de formar a individualizar seus interesses e predileções para que a atividade escolar que desenvolve faça conexões com a sua vida e suas expectativas de aprendizagem. E para isto, é de extrema relevância os profissionais que atuam com esse estudante conhecerem e compreenderem as características desse transtorno para melhor saber se colocarem frente aos desafios que demandam aos que atuam diretamente com ele. Para Belizário Filho e Lowenthal (2013) é nesse espaço que esse estudante pode aprender com outras crianças, exercitar a sociabilidade por mais comprometida que seja e, finalmente, exercer um direito agora disponível a ele, o da educação.

Outro aspecto que necessita ser levado em consideração no trabalho a ser desenvolvido no espaço da biblioteca junto aos estudantes com espectro autista é a comunicação verbal e não verbal. A linguagem verbal deve ser estimulada para aumentar o repertório de linguagem.

É preciso apresentar as variações linguísticas e seu uso em diversas situações do cotidiano. Podese utilizar para facilitar a aprendizagem o uso de imagens associadas às frases para os estudantes perceberem essa variação.

A linguagem escrita, a não falada e a verbal, são constituídas por sinais que emitimos o tempo inteiro na interação com o outro, sejam pela fala, gestos, olhares, expressões corporais e faciais. Algumas pessoas com espectro autista não possuem a capacidade de avaliar essas formas de comunicação. Para Bosa (2001, p. 3):

\footnotetext{
As pessoas com autismo experienciariam uma sobrecarga sensorial durante a interação social, considerando-se que o ser humano é uma das fontes mais ricas de estimulação simultâneas: tom da voz (estímulos auditivos); expressão facial (estímulo visual); gestos (estímulo visual periférico) e referência a objetos e eventos ao redor (estímulo visual e auditivo periférico). O retraimento social e as estereotipias seriam formas de fugir dessa sobrecarga.
}

Outros autores que fazem inferências acerca do tema linguagem na pessoa com espectro autismo são Silva, Gaiato e Reveles (2012). Ele acrescenta que a pessoa com espectro autista tem prejuízos na capacidade de avaliação através dos sentidos o que prejudica a interpretação dos fatos que ocorrem ao seu 


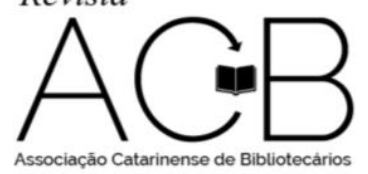

Revista ACB: Biblioteconomia em Santa Catarina, Florianópolis, v. 23, n. 1, p. 92-106, dez./mar., 2018.

redor. Esses autores assinalam que: "algumas falhas ou problemas na evolução da linguagem constituem os primeiros sinais de que o desenvolvimento de uma criança não está conforme o esperado e podem sugerir um funcionamento autístico”. (SILVA; GAIATO; REVELES, 2012, p. 30).

Segundo Bosa (2001) a atenção compartilhada está diretamente relacionada à maturação dos lobos frontais e aparece no segundo semestre da vida do bebê. Segundo o autor, o processo de atenção engloba quatro elementos e são eles: focalização, sustentação, deslocamento e decodificação da atenção, sendo que estes elementos se localizam em diferentes áreas cerebrais.

Uma das características persistente do autismo é a falta de tendência de unir as partes ao todo para formar um significado, tendo coesão central. Continuando no tema, esse mesmo autor traz contribuições acerca da teoria da mente ao defini-la como a capacidade de atribuir estados mentais, como por exemplo: desejos, conhecimentos, pensamentos e crenças a outras pessoas e predizer o comportamento das mesmas diante dessas atribuições.

E isso acarreta em problemas de comunicação que englobam repetir frases e palavras (ecolalia); inverter os pronomes, não responder de forma adequada ao que lhe é perguntado; apresentar fala monótona; e não compreender e interpretar as nuances da língua como o sarcasmo, a ironia e os provérbios.

Silva, Gaiato e Reveles (2012) demarcam que a ecolalia é uma característica do transtorno que faz com que pessoas com espectro autismo repitam os sons ouvidos que são proferidos por um emissor, instantaneamente ou em momento posterior, e que não necessariamente estejam estabelecendo um diálogo com ele. Silva, Gaiato e Reveles (2012) acentuam que a fala pode parecer robotizada e em alguns casos excessivamente aguda.

Atualmente a classificação e diagnóstico da pessoa com espectro autismo é feita seguindo os seguintes critérios descritos pela Associação de Psiquiatria Americana (1995) no Manual Diagnóstico e Estatística de Transtornos Mentais (DSM-IVTR):

A. Um total de seis (ou mais) itens de (1), (2) e (3), com pelo menos dois de (1), um de (2) e um de (3):

(1) Prejuízo qualitativo na interação social, manifestado por pelo menos dois dos seguintes aspectos:

(a) Prejuízo acentuado no uso de múltiplos comportamentos não verbais tais como contato visual direto, expressão facial, posturas corporais e gestos para regular a interação social;

(b) Fracasso em desenvolver relacionamentos com seus pares apropriados ao nível do desenvolvimento;

(c) Falta de tentativa espontânea de compartilhar prazer, interesses ou realizações com outras pessoas (por exemplo, não mostrar, trazer ou apontar objetos de interesse);

(d) Falta de reciprocidade social ou emocional;

(2) Prejuízos qualitativos da comunicação, manifestados por pelo menos um dos seguintes aspectos:

(a) Atraso ou ausência total de desenvolvimento da linguagem falada (não acompanhando por uma tentativa de compensar por meio de modos alternativos de comunicação tais como gestos ou mímica), em indivíduos com fala adequada;

(b) Acentuado prejuízo na capacidade de iniciar ou desenvolver uma conversação;

(c) Uso estereotipado e repetitivo da linguagem (pode aparecer ecolalia) ou linguagem idiossincrática;

(d) Falta de jogos ou brincadeiras de imitação social variada e espontâneos apropriados ao nível do desenvolvimento. 


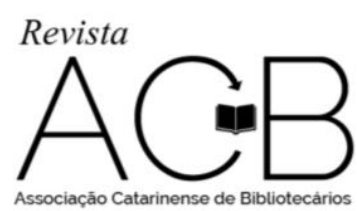

Revista ACB: Biblioteconomia em Santa Catarina, Florianópolis, v. 23, n. 1, p. 92-106, dez./mar., 2018.

(3) Padrões restritos e repetitivos de comportamentos, interesses, e atividades, manifestados por pelo menos um dos seguintes aspectos:

(a) Preocupação insistente com um ou mais padrões estereotipados e restritos de interesse, anormais em intensidade ou foco;

(b) Adesão aparentemente inflexível a rotinas ou rituais específicos e não funcionais;

(c) Maneirismos motores estereotipados e repetitivos (por exemplo, agitar ou torcer mãos ou dedos, ou movimentos complexos de todo o corpo);

(d) Preocupação persistente com partes de objetos, não atentando para aspectos relevantes do meio.

B. Atrasos ou funcionamento anormal em pelo menos uma das seguintes áreas, com início antes dos três anos de idade:

(a) Interação social;

(b) Linguagem para fins de comunicação social;

(c) Jogos imaginativos ou símbolos;

C. O distúrbio não é melhor explicado por Transtorno de Rett ou Transtorno Desintegrativo da infância.

\section{Outro critério utilizado para realização do diagnóstico do espectro autismo é a Classificação} Internacional de Doenças (CID 10), de 1993, para o que, pelo menos oito dos 16 itens especificados a seguir devem ser satisfeitos:

a) Lesão marcante na interação social recíproca, manifestada por pelo menos três dos próximos cinco itens:

1. Dificuldade em usar adequadamente o contato ocular, expressão facial, gestos e postura corporal para lidar com a interação social;

2. Dificuldade no desenvolvimento de relações de companheirismo;

3. Raramente procura conforto ou afeição em outras pessoas em tempos de tensão ou ansiedade, e/ou oferece conforto ou afeição a outras pessoas que apresentem ansiedade ou infelicidade;

4. Ausência de compartilhamento de satisfação com relação a ter prazer com a felicidade de outras pessoas e/ou de procura espontânea em compartilhar suas próprias satisfações por meio do envolvimento com outras pessoas;

5. Falta de reciprocidade social e emocional.

b) Marcante lesão na comunicação:

1. Ausência de uso social de quaisquer habilidades de linguagem existentes;

2. Diminuição de ações imaginativas e de imitação social;

3. Pouca sincronia e ausência de reciprocidade em diálogos;

4. Pouca flexibilidade na expressão de linguagem e relativa falta de criatividade e imaginação em processos mentais;

5. Ausência de resposta emocional a ações verbais e não verbais de outras pessoas;

6. Pouca utilização das variações na cadência e ênfase para refletir a modulação comunicativa;

7. Ausência de gestos para enfatizar ou facilitar a compreensão na comunicação oral.

c) Padrões restritos, repetitivos e estereotipados de comportamento, interesses e atividades, manifestados por pelo menos dois dos próximos seis itens:

1. Obsessão por padrões estereotipados e restritos de interesse;

2. Apego específico a objetos incomuns;

3. Fidelidade aparentemente compulsiva a rotinas ou rituais não funcionais específicos;

4. Hábitos motores estereotipados e repetitivos;

5. Obsessão por elementos não funcionais ou objetos parciais do material de recreação;

6. Ansiedade com relação a mudanças em pequenos detalhes não funcionais do ambiente.

d) Anormalidades de desenvolvimento devem ter sido notadas nos primeiros três anos para que o diagnóstico seja feito.

Diante dos critérios de diagnóstico de autismo, é necessário que o profissional da biblioteca esteja atento ao comportamento dos estudantes com espectro autista, pois alguns podem apresentar estereotipias e comportamentos de autoestimulação, persistência em determinadas situações, além de ser afetado por quadros de isolamento e em alguns casos mais graves a depressão. 
Conhecendo as características os profissionais que atuam na biblioteca poderão desenvolver serviços que atendam as demandas informacionais dos usuários autistas.

\section{OS SERVIÇOS DA BIBLIOTECA ESCOLAR E O LETRAMENTO INFORMACIONAL ATRAVÉS DO DESENHO UNIVERSAL}

Os profissionais de ensino que atuam na biblioteca escolar podem desenvolver práticas pedagógicas que possibilitem a construção do conhecimento para os usuários. Esta ideia é abraçada por Roca (2012), que destaca a necessidade de ela estar integrada ao projeto curricular e educacional da escola para que se converta em elemento ativo que favoreça os processos de ensino e aprendizagem, apoiando o trabalho docente.

Para os usuários com autismo, essa possibilidade é particularmente auspiciosa ao se considerar que as ações educativas em prol dos alunos são compreendidas em boa parte pela da prática do letramento informacional. O termo "letramento informacional" (information literacy), segundo Campello (2009), foi usado pela primeira vez na década de 1970, para caracterizar competências necessárias ao uso de fontes eletrônicas de informação que estavam sendo produzidas nos Estados Unidos na época, sendo definido por Gasque (2012) como sendo a ação contínua e prolongada como processo de aprendizagem necessário ao desenvolvimento de competências e habilidades específicas para buscar e usar a informação para construção do conhecimento inerente ao ser humano.

As observações de Dretske $^{3}$ (1991, apud Capurro; Hjorland, 2007), de que embora seja uma condição necessária à aquisição de conhecimento, a informação não requer um processo interpretativo, e de Buckland (1991), de que a informação-como-coisa incluem textos, documentos, dados, objetos e eventos, são úteis para embasar as ações de letramento informacional para usuários autistas.

Buckland (1991, p. 352) destaca a noção da "informação-como-coisa" na comunicação da “informação-como-conhecimento", afirmando:

\footnotetext{
Uma característica chave da "informação-como-conhecimento" é de que é intangível: não se pode tocá-la ou medi-la, de modo algum. Conhecimento, convicção e opinião são atributos individuais, subjetivos e conceituais. Entretanto, para comunica-los, eles têm que ser expressos, descritos ou representados, de alguma maneira física, como um sinal, texto ou comunicação. Qualquer expressão, descrição ou representação séria "informação-como-coisa. (BUCKLAND, 1991, p. 352).
}

A informação pode ser visual para as pessoas com autismo. Através do contato com imagens, possibilita a comunicação, principalmente para aqueles que possuem ou apresentam dificuldade na fala. Vieira (2012, p.14) propõe o método Picture Exchange Communcation System (PECS) para ensinar

\footnotetext{
${ }^{3}$ DRETSKE, K. J. Logic and information. Cambridge, UK: Cambridge University, 1991.
} 


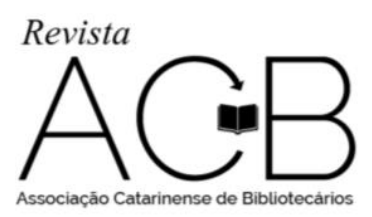

Revista ACB: Biblioteconomia em Santa Catarina, Florianópolis, v. 23, n. 1, p. 92-106, dez./mar., 2018.

pessoas com distúrbios de comunicação e/ou com autismo a se comunicarem de forma funcional por intermédio da troca de figuras, como no exemplo abaixo, na figura 1.

\section{Figura 1: Comportamentos esperados / comportamentos inesperados}

Fonte: Mayer-Johnson (2010, p. 21).

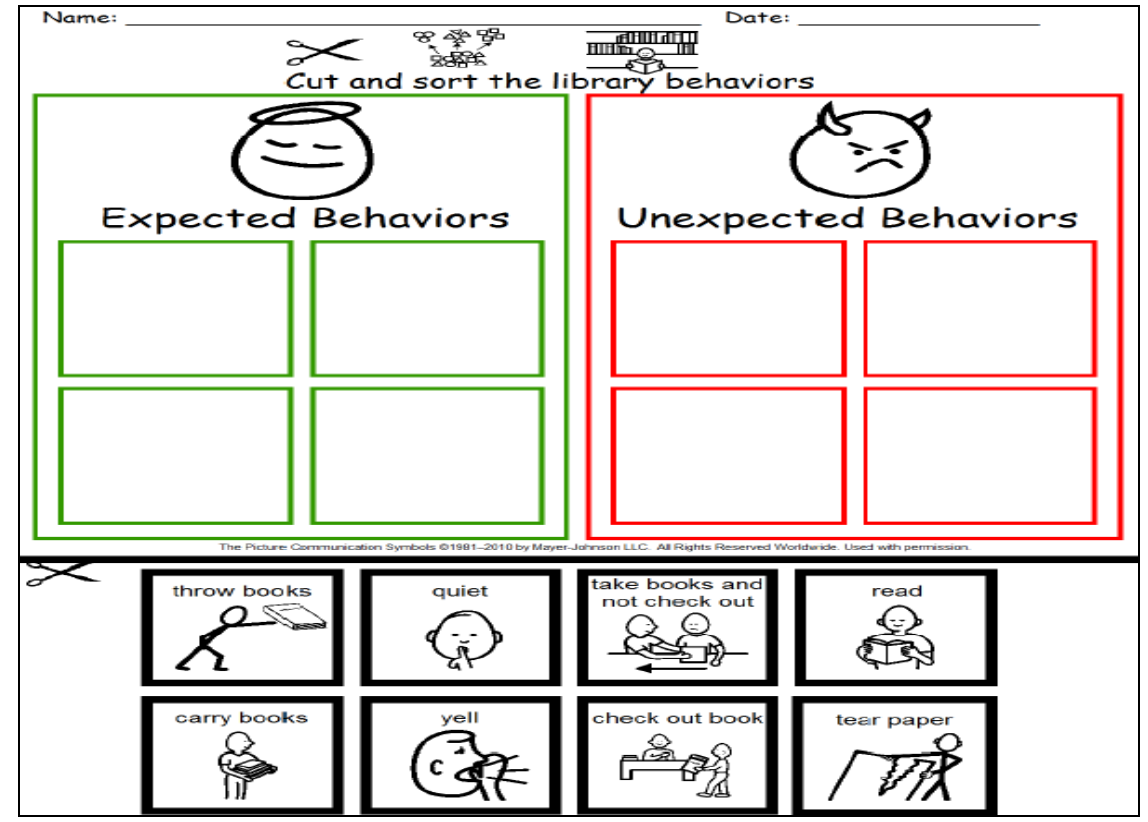

Nesta atividade prática a ser desenvolvida na biblioteca, o usuário autista irá recortar e colar as figuras nos campos correspondentes ao comportamento esperado no uso do espaço. Outras atividades que poderão ser desenvolvidas com o usuário poderá ser o reconhecimento do espaço da biblioteca, os indivíduos (usuário, bibliotecário, professor, comunidade escolar) e os signos (livro, revista, computador, estante, balcão de atendimento) que estão presentes neste espaço na figura 2. 


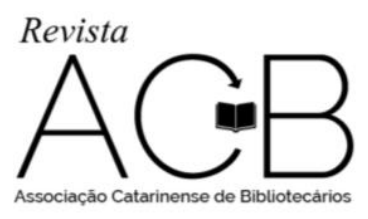

Revista ACB: Biblioteconomia em Santa Catarina, Florianópolis, v. 23, n. 1, p. 92-106, dez./mar., 2018.

\section{Figura 2: Símbolos de cartão}

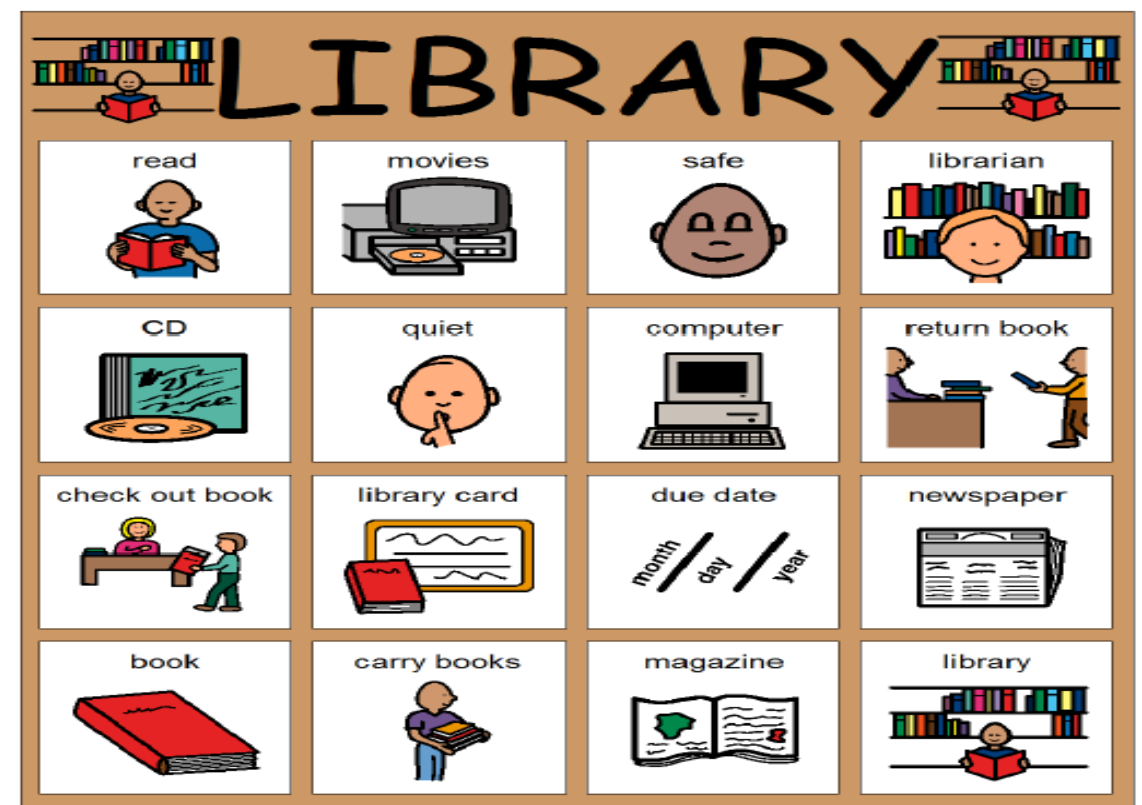

Fonte: Mayer-Johnson (2010, p. 12).

Os serviços de biblioteca preocupados em atender as demandas informacionais dos usuários com autismo vão além da prática de acessibilidade. Atualmente, a literatura permite a discussão de se pensar à biblioteca como espaço de exercício do letramento informacional do aluno através da perspectiva do desenho universal. O desenho universal não é direcionado apenas para as pessoas com deficiência mas amplia a gama de atendimento para as pessoas com necessidades especiais, que podem ser inclusas as pessoas obesas, gestante, com problemas de coração, dificuldade acentuada de aprendizagem.

Nesse sentido, pode ser muito útil às práticas do Desenho Universal (DU), que é explicado pelo artigo 2 do Decreto $n^{\circ}$ 6.949/09 como sendo a "[...] concepção de produtos, ambientes, programas e serviços a serem usados, na maior medida possível, por todas as pessoas, sem necessidade de adaptação ou projeto específico". Dando continuidade, o mesmo texto legal alerta que "o "desenho universal" não excluirá as ajudas técnicas para grupos específicos de pessoas com deficiência, quando necessárias”. Isto é, nesses casos, o DU se torna específico, buscando atender o caso em consideração.

O DU inclui projetos, equipamentos, interiores e exteriores de edifícios, sistemas de transportes, áreas urbanas e, também, tecnologia da informação e comunicação para todos sem distinções de gênero, etnia, saúde, situações e fatores correlatos, segundo citados por Santos Filho (2010), o qual destaca nesse método de projeto as diversas diretrizes para sua realização, sendo muito utilizada a dos sete princípios do Center of Universal Design, da North Carolina State University (2014), que recomenda para a proposição, desenvolvimento e uso de projetos de produtos e espaços, se considerar: 


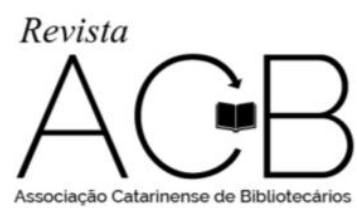

Revista ACB: Biblioteconomia em Santa Catarina, Florianópolis, v. 23, n. 1, p. 92-106, dez./mar., 2018.

1. O uso equitativo pelas pessoas com diversas habilidades, evitando discriminação;

2. A flexibilidade no uso para diversas capacidades;

3. A simplicidade e intuitividade do uso;

4. A percepção fácil e eficiente da informação para uso;

5. A tolerância ao erro, minimizando consequências indesejáveis pelo uso incorreto;

6. A redução do esforço físico;

7. A previsão de tamanho e espaço para o uso em diferentes situações.

Um importante elemento para a acessibilidade para esse mesmo autor (2010) é o referente às Tecnologias Assistivas, as quais são tecnologias para desempenhar tarefas, projetadas especialmente ou por mudança de métodos nas tecnologias tradicionais, devendo seguir diretrizes do DU e na sua impossibilidade, as normas ditam os limites. Nas normas, destacam-se a ABNT NBR 9050: 2015, para o espaço arquitetônico, a NBR 10152:1987 Versão Corrigida:1992, incorpora a Errata de 30/06/1992, sobre o conforto acústico em ambientes diversos; a ABNT NBR ISO/CIE 8995-1:2013, sobre a iluminação de ambientes de trabalho; e a ABNT NBR 15599:2008, sobre serviços.

Maroto (2012) alerta que os profissionais não podem esquecer de que o fazer educativo constituise, mais especificadamente no desenvolvimento de ações de mediação e de incentivo à leitura e à pesquisa junto à comunidade escolar. Ocorre que esse fazer resulta dos serviços oferecidos pela biblioteca.

As especificidades dos alunos com deficiência, que determinam as ações dos profissionais da biblioteca sobre acessibilidade informacional, devendo respeitar as singularidades de cada aluno.

Somente superando os desafios de implementação do letramento informacional na biblioteca através da implantação desta ação no Projeto Político Pedagógico (PPP) da unidade escolar, é possível discutir com a comunidade escolar a necessidade de estabelecer iniciativas em prol da leitura e da aquisição de conhecimento para os alunos com autismo.

\section{CONSIDERAÇÕES FINAIS}

O estudo enfatiza que os profissionais da biblioteca escolar em ações multidisciplinar com os demais do sistema educacional necessitam criar práticas de letramento informacional que visem superar as barreiras arquitetônicas e atitudinais na escola e na própria biblioteca escolar, possibilitando um olhar atento para os alunos com autismo, e procurar quais são as dificuldades e potencialidades destes estudantes para que o trabalho seja direcionado e atento às necessidades específicas de aprendizagem de cada indivíduo. 
Trata do design universal, que não se resume à acessibilidade física da biblioteca escolar, à arquitetura e ao desenvolvimento de produtos, devendo ser utilizado como meio de acomodar e incluir todos os tipos de discentes, com ou sem deficiência.

Finalmente, considerando que há milhares de bibliotecas escolares no Brasil, conclui como necessário o despertar do interesse dos governantes em investir recursos e buscar parcerias com instituições especializadas para contribuir para tornar esses locais como um espaço de possibilidades de transformação social, de mudança do olhar sobre a pessoa com transtorno do espectro autista para oferecer-lhes um mundo tangível à sua compreensão por meio da leitura.

\section{REFERÊNCIAS}

ARAUJO, Álvaro Cabral; LOTUFO NETO, Francisco. A nova classificação americana para os transtornos mentais: o DSM-5. Revista Brasileira de Terapia Comportamental e Cognitiva, São Paulo, v.16, n. 1, p. $67-82,2014$. Disponível em: <http://www.usp.br/rbtcc/index.php/RBTCC/article/view/659/406>. Acesso em: 17 abr. 2017.

ASSOCIAÇÃO BRASILEIRA DE NORMAS TÉCNICAS (ABNT). ABNT NBR 9050: 2015. Acessibilidade a edificações, mobiliário, espaços e equipamentos urbanos. 11 de novembro de 2015. Disponível em: < https://www.abntcatalogo.com.br/norma.aspx?ID=344730>. Acesso em: 24 abr. 2017.

. ABNT NBR 10152:1987 Versão Corrigida:1992, incorpora a Errata de 30/06/1992. Esta Norma fixa os níveis de ruído compatíveis com o conforto acústico em ambientes diversos. 30 Jun. 1992. Disponível em: <https://www.abntcatalogo.com.br/norma.aspx?ID=4564>. Acesso em: 19 abr. 2017.

NBR ISO/CIE 8995-1:2013. Iluminação de ambientes de trabalho. Parte 1: Interior. Disponível em: <https://www.abntcatalogo.com.br/norma.aspx?ID=196479>. Acesso em: 23 abr. 2017.

NBR 15599:2008. Acessibilidade - Comunicação na prestação de serviços. . 25 ago. 2008. Disponível em: < https://www.abntcatalogo.com.br/norma.aspx?ID=1451>. Acesso em: 15 abr. 2017.

ASSOCIAÇÃO PSIQUIATRICA AMERICANA. Manual de Diagnóstico e Estatística de Transtornos Mentais (DSM-IV). Porto Alegre: Artes Médicas, 1995.

ASSUMPÇÃO JR., F.B. Conceito e classificação das síndromes autísticas. In: SCHWARTZMAN, J. S; ASSUMPÇÃO JR., F.B. Autismo Infantil. São Paulo: Memnon, 1995.

BOSA Cleonice Alves. As relações entre autismo, comportamento social e função executiva. Psicologia: Reflexão e Crítica, v.14, n.2, p.281-287, 2001. Disponível em:

<http://www.scielo.br/pdf/prc/v14n2/7855.pdf>. Acesso em: 05 jun. 2017.

BELIZÁRIO FILHO, José; LOWENTHAL, Rosane. A inclusão escolar e os transtornos do espectro do autismo. In: SCHMIDT, Carlos (Org.). Autismo, educação e transdisciplinaridade. Campinas, SP: Papirus, 2013. 
Decreto $n^{0}$ 6.949, de 25 de agosto de 2009. Promulga a Convenção Internacional sobre os Direitos das Pessoas com Deficiência e seu Protocolo Facultativo, assinados em Nova York, em 30 de março de 2007. Diário Oficial [da] República Federativa do Brasil, Brasília, DF, 26 ago. 2009. Disponível em: <http://www.planalto.gov.br/ccivil_03/_Ato2007-2010/2009/Decreto/D6949.htm>. Acesso em: 17 abr. 2017.

Lei n. ${ }^{\circ}$ 7.853, de 24 de outubro de 1989. Dispõe sobre o apoio às pessoas portadoras de deficiência, sua integração social, sobre a Coordenadoria Nacional para Integração da Pessoa Portadora de Deficiência - Corde, institui a tutela jurisdicional de interesses coletivos ou difusos dessas pessoas, disciplina a atuação do Ministério Público, define crimes, e dá outras providências. Brasília, DF, 1989.

. Lei n. ${ }^{\circ}$ 9.394, de 20 de dezembro de 1996. Estabelece as diretrizes e bases da educação nacional. Brasília, DF, 1996.

Lei n. ${ }^{\circ}$ 12.764, de 27 de novembro de 2012. Institui a Política Nacional de Proteção dos Direitos da Pessoa com Transtorno do Espectro Autista; e altera o § 3o do art. 98 da Lei no 8.112, de 11 de dezembro de 1990. Brasília, DF, 2012.

Portaria n ${ }^{\circ} 55$, de 2007, prorrogada pela Portaria n⿳0 948/2007. Política Nacional da Educação Especial na Perspectiva da Educação Inclusiva. Brasília: MEC/SEESP, 2008.

BUCKLAND, Michael Keeble. Information as thing. Journal of the American Society for Information Science, v.45, n.5, p.351-360, 1991.

CAMPELLO, Bernadete. Letramento informacional: práticas educativas de bibliotecários em escolas de ensino básico. 2009. 207f. Tese. (Doutorado em Ciência da Informação) - Escola de Ciência da Informação, Universidade Federal de Minas Gerais, Belo Horizonte, 2009.

CAPURRO, Rafael; HJORLAND, Birger. O conceito da informação. Perspectivas em Ciência da Informação, v.12, n.1, jan./abr. 2007.

CENTERS FOR DISEASE CONTROL AND PREVENTION. Prevalence of autism spectrum disorder among children aged 8 years: autism and developmental disabilities monitoring network, 11 Sites, United States, 2010. CDC, v.63, n.2, p.1-21, 2014.

\section{CLASSIFICAÇÃO DE TRANSTORNOS MENTAIS E DE COMPORTAMENTO DA CID-10; Descrições clínicas e diretrizes diagnósticas. Porto Alegre: Artes Médicas, 1993.}

GASQUE, Kelley Cristine Gonçalves Dias. Letramento Informacional: pesquisa, reflexão e aprendizagem. Brasília: Universidade de Brasília, 2012. E-book. Disponível em: <http://leunb.bce.unb.br/bitstream/handle/123456789/22/Letramento_Informacional.pdf?sequence=3>. Acesso em: 15 jul. 2017.

MAROTO, Lucia Helena. Biblioteca escolar, eis a questão! Do espaço do castigo ao centro do fazer educativo. 2ed. Belo Horizonte: Autêntica Editora, 2012.

MAYER-JOHNSON, Roxanna. Guia de símbolos de comunicação pictórica. Porto Alegre: Clik, 2010. 64p. il. 


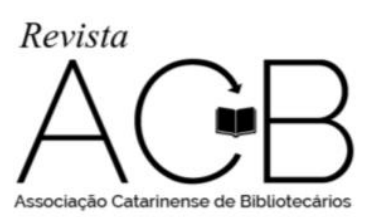

Revista ACB: Biblioteconomia em Santa Catarina, Florianópolis, v. 23, n. 1, p. 92-106, dez./mar., 2018.

RITVO, E.R.; ORNITZ, E.M. Medical Assesment. In: RITVO, E.R. (Ed.). Autism: diagnosis, current research and management. Spectrum: New York, 1976.

ROCA, Glória Durban. Biblioteca escolar hoje: recurso estratégico para a escola. Porto Alegre: Penso, 2012.

SANTOS FILHO, Gildo M. Construindo um itinerário histórico do desenho universal: a normatização nacional e internacional da acessibilidade. In: ORNSTEIN, Sheila Walbe; ALMEIDA PRADO, Adriana R.; LOPES, Maria Elizabete (Orgs). Desenho Universal: caminhos da acessibilidade no Brasil. São Paulo: Annablume, 2010.

SILVA, Ana Beatriz Barbosa; GAIATO, Mayra Bonifacio; REVELES, Leandro Thadeu. Mundo singular: entenda o autismo. Rio de Janeiro: Objetiva, 2012.

VIEIRA, Soraia Cunha Peixoto. O que é PECS? Revista Autismo, v.2, n.2, abr. 2012.

\section{MARCOS PASTANA SANTOS}

Doutorando em Humanidades, Culturas e Artes na Universidade do Grande Rio (UNIGRANRIO). Mestre Profissional em Biblioteconomia na Universidade Federal do Estado do Rio de Janeiro. BibliotecárioDocumentalista do Instituto Federal do Rio de Janeiro - IFRJ. E-mail: marcos.pastana@ ifrj.edu.br

\section{CLÁDICE NÓBILE DINIZ}

Doutora em Ciência da Informação na Universidade Federal do Rio de Janeiro (UFRJ). É docente e pesquisadora no Programa de Pós-Graduação em Biblioteconomia e no Departamento de Engenharia de Produção da Universidade Federal do Estado do Rio de Janeiro (UNIRIO). É líder do grupo de pesquisa: Perspectivas da biblioteca como organização criativa na otimização dos recursos de aprendizagem: da acessibilidade à fluência informacional. E-mail: cladice.diniz@unirio.br 